no spacing at all in call numbers. Catalog librarians would have been able to warn us of these authority and database problems, and we would then have written the data entry form to ask for information directly usable by our student assistant without the added step of our having to make corrections.

Catalogers would also have advised that we write our lists by index rather than by subject heading (i.e., list subjects for indexes rather than indexes for subjects), so the student assistant would have to modify each Innovacq record only once. This would have cut down on the hours required for data entry. The Cataloging Department could have been of great help in determining specificity levels for subject headings. Some subject specialists (the "lumpers") created only a few long lists with quite general subject headings, while others (the "splitters") broke their topics into several short lists of more specific subjects. This created the potential for confusion on the part of librarians and patrons who would not know whether to look under more general or specific subject headings for their topic.
To alleviate this problem partially, we included a number of cross references in our table of contents list of subject headings.

Future implications include the possibility of transferring SGPI to disk, with Innovacq's permission, so patrons could access the information either in print or via a computer located in the reference area. This might also allow us to modify its printed format in order to create a more attractive final product.

\section{Conclusion}

We have observed several students and librarians using the Subject Guide during the semester it has been available in our reference area. It is serving our original purposes of increasing patron independence, assisting new librarians in becoming familiar with the index collection, and helping student assistants work with patrons during late hours when librarians do not staff the reference desk.

\title{
A faculty retreat: Coping with challenges
}

\author{
By Mary M. Nofsinger \\ Public Services Librarian \\ Washington State University
}

\author{
and Mary Gilles \\ Public Services Librarian \\ Washington State University
}

After an unusually hectic, stressful Fall Semester working with 16,000 undergraduate students, the public services librarians in the humanities/social sciences library at Washington State University decided they needed to assess priorities and clarify future directions. The unit's first retreat presented an opportunity to discuss recent problems and successes as well as a chance to consider long-range issues which could not be dealt with adequately during busy weekly faculty meetings. It also provided time to analyze and recoup losses, encouragement to improve communication with colleagues, and the challenge of anticipating future developments which will affect academic librarianship.

When the idea of a faculty retreat was initially suggested, strong support was expressed by librarians and unit administrators. Plans were made to meet during Christmas Intersession when classes were not held. An additional librarian was hired to staff the reference desk so that all humanities/social sciences librarians could attend the day-long retreat. To avoid distractions, it was agreed that an off-campus community meeting room would be preferable. As Christmas approached, topics for discussion were proposed. An agenda was devel- oped, and participating librarians were solicited to serve as discussion leaders for the following topics:

1. The future of reference service.

2. Collection development issues.

3. External access to the WSU Libraries' online catalog and effects on our services.

4. User instruction in the future.

5. New automation needs.

6. Professional development of librarians.

7. Organizational, budgetary, and personnel constraints/opportunities.

8. Directions for the coming year.

Discussion of the future of reference service began with a review of social, demographic, and academic variables which are projected to impact our profession in the foreseeable future. Lively and varied comments were presented on current reference issues, including discussion of the neverending necessity for balancing conflicting demands for time among reference, collection development, user education, database searching, and other responsibilities. Also discussed was the possibility of an Information Desk staffed with paraprofessionals, streamlining reference duties, office hours for librarians, improving the accuracy of reference 
assistance, reference consultation by appointment only, making users more self-sufficient, and the feasibility of offering online ready-reference service daily without fees.

Next, the heads of social sciences and humanities collection development reviewed the dismal budget situation for the remainder of the fiscal year as well as projections for financing in the next biennium. Escalating costs of serials due to inflation, the decline in the purchasing power of the dollar overseas, and the price-gouging of a few foreign publishers were also discussed. Reduced spending procedures were emphasized, including the continuing need to cancel one-and-a-half subscriptions for each new serial ordered. There was general agreement among the librarians that revision of collection development policy statements needed to be completed in 1989, and that weeding should be given higher priority due to space shortages.

Another potential problem, the steadily increasing usage of the WSU Libraries' collections and services by students from a nearby university, was discussed. Information was presented regarding a recently negotiated agreement with another university which will allow additional public access to the WSU Libraries' online catalog. It was also revealed that massive increases in circulation and lending activities occurred this past year, depleting current staffing resources. Ramifications for the future were discussed, along with the projected impact of anticipated growth in the usage of library materials. Possible courses of action to alleviate the situation were pondered, but easy solutions were not readily apparent.

Just before a congenial lunch break, the user education librarian discussed plans for dealing with large classes of students who need library instruction each semester. Discussion emphasized the need for incorporating more active learning techniques in class presentations to increase student motivation. Also briefly mentioned was the need for more creative experimentation with other possible alternatives such as audiotapes, peer tutoring on library assignments, and collaborative learning in small groups. As for long-range planning, the librarians agreed that course-integrated user instruction for all freshmen students was still a strong, but elusive, objective which we must continue to pursue.

In the afternoon, current and future automation needs were discussed, including an easy-access online catalog menu which will soon be available and the increasing numbers of CD-ROM products in many subject disciplines. Obtaining increased funding and adapting microcomputers for use with multiple products were seen as major problems with offering these popular services. With serial budget restrictions so tight, even the purchase of another CD-ROM would significantly affect collection development funds. Next, the need for better end-user training was briefly explored, as well as the possibility of loading national databases on the WSU mainframe for campus use. With few suggestions to ease automation needs, the librarians acknowledged that acquiring new technologies still presented challenges.

Discussion of the professional development of librarians produced an interesting diversity of opinions and ideas. Brainstorming provided a long list of resources needed by librarians, including released time from regular duties, funding, student/ secretarial support, setting aside time daily, written policies, etc. Then, the conversation turned to specific actions which would facilitate getting those resources in the future. There was considerable support for a proposal to negotiate with the unit head for released time from daily duties for short professional projects. Other topics included greater use of professional leaves for tenured librarians, creating a floating librarian position to perform duties of librarians released for projects, and developing a written unit policy on negotiated time.

Lastly, organizational, budgetary, and personnel issues for the future were considered. The head of Humanities/Social Sciences Public Services reviewed projections for legislative funding in the next biennium, the most pressing budgetary needs of the unit, and efforts to improve long-term planning. Discussion of two staff vacancies revealed some interesting possibilities for the administration and reorganization of services provided for current journals, bound journals, and microfilm. Issues to consider regarding the proposed new building and remodeling plans were also briefly presented, although optimism was restrained since funding had not yet been approved by the state legislature.

At the conclusion of a lively and informative day, consensus was reached on a manageable number of issues to pursue in 1989. Priorities had been established, and decisions as well as follow-up activities were clearly identified. Although the discussions had been emotionally intense, the librarians felt optimistic that many excellent suggestions and ideas stimulated during the retreat would be implemented. In effect, participating librarians rejected the negative attitude of "nothing can be done." Instead, they chose to take positive, assertive actions toward meeting the challenges of the future.

\section{Correction}

The FY 1988 revenue figures for Rare Books and Manuscripts Librarianship and the ACRL nonperiodical publications were erroneously transposed in the article on "ACRL's 1988/89 budget" in the April 1989 issue of C\&RL News, p. 306 . The actual figure for $R B M L$ is $\$ 12,372$ and for the nonperiodical publications is $\$ 61,710$. 
Staying up-to-the-minute with the fast-breaking research that is shaping our future has never been easier with...

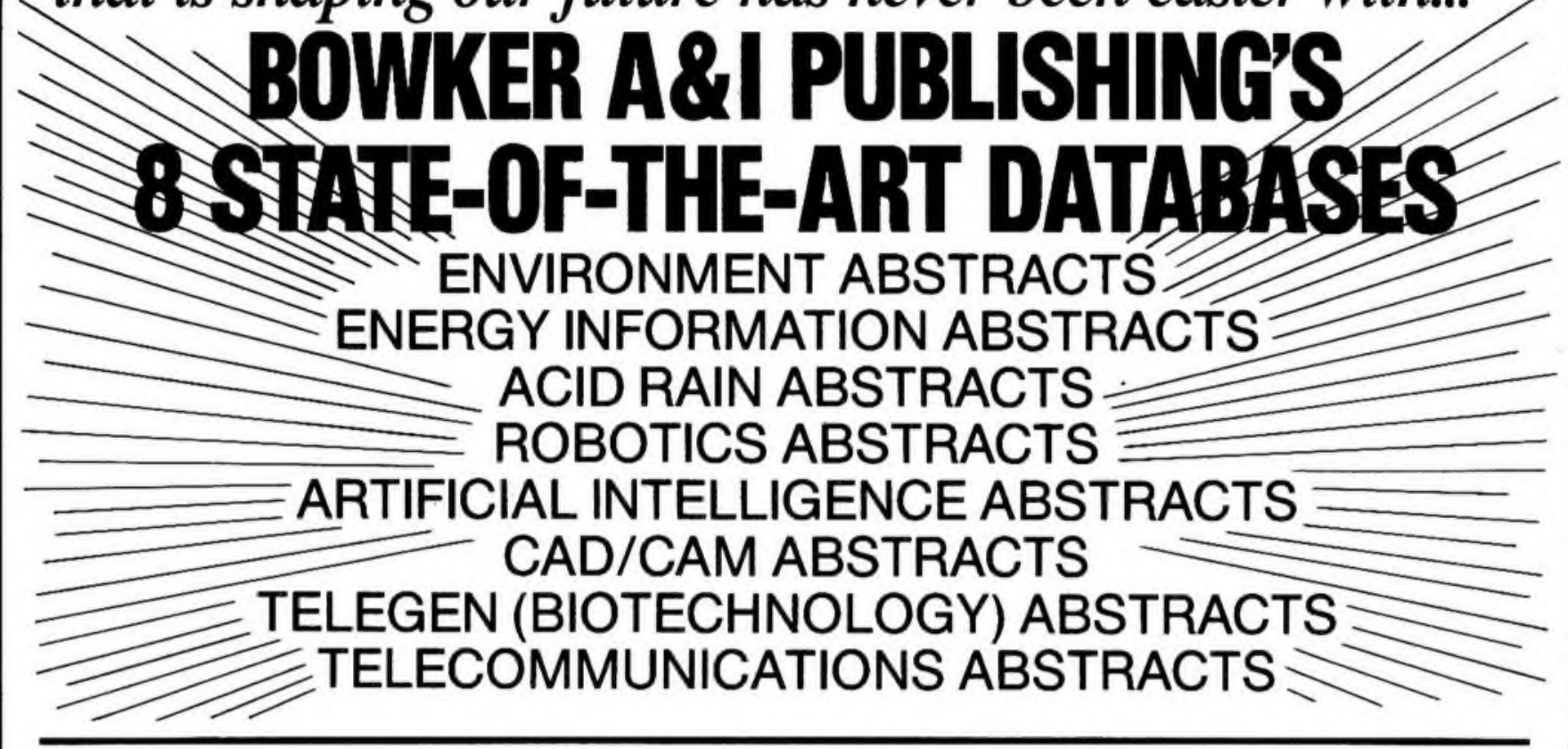

...because every month Bowker's eight carefully compiled journals abstract and index thousands of articles on environmental studies, energy, acid rain*, robotics, artificial intelligence, $C A D / C A M$, biotechnology, and telecommunications. The information found in each publication is drawn from over 1,700 international scientific, economic, technical, academic, and trade journals plus scores of leading general-circulation newspapers, magazines, and wire services.

\section{More than just journals.}

Better still, our journals are part of a sophisticated document retrieval system that lets you order comprehensive microfiche collections carrying the full text of over $80 \%$ of the articles we cite. And you can order microfiche or paper copies of individual articles on a per-document basis as well. In addition, all eight databases are available online from the top online services.

What's more, Bowker A \& I Publishing's journals bring together the "grey" or elusive literature -- conference proceedings, government studies, scientific association reports, even patents -- that often is neither indexed or available in any readily accessible medium.

So whether you're looking for the latest findings on gene products, ozone depletion, nonconventional fuels, U.S. acid rain policy, robot locomotion, human-machine interfaces, or any of hundreds of other crucial high-tech issues, don't bury yourself in indexes or burden yourself with serials orders.

${ }^{*}$ Acid rain is abstracted and indexed every two months.

\section{Look to Bowker A \& I Publishing to keep you current with the literature. You'll not only make a small research breakthrough yourself...you'll make a big one easier for your patrons, too.}

\section{Call Now For a Free Sample Journal!}

TO ORDER - OR FOR MORE INFORMATION ABOUT OUR INTEGRATED SYSTEM OF MONTHLY JOURNALS, ANNUAL INDEXES, MICROFICHE, AND ONILINE DATABASES -- CALL

TOLLRREE 1-800-521-8110 (IN NY, AK, OR HI CALL COLLECT 1-212-463-6869).
B O W KE R

Formeriv EIC/Antelligence
R.R. Bowker, 245 West 17 Street. New York, NY 10011 